\title{
Does teaching methodology affect medication dosage calculation skills of undergraduate nursing students?
}

\author{
Kristie Riddle, Lindsay Domiano \\ School of Nursing, Southeastern Louisiana University, United States
}

Received: September 19, 2019

DOI: $10.5430 /$ jnep.v10n3p36
Accepted: November 22, 2019 Online Published: November 25, 2019

URL: https://doi.org/10.5430/jnep.v10n3p36

\begin{abstract}
One of the most critical functions of a nurse is the safe administration of medications. To ensure patient safety, nurses must be competent in medication dosage calculation (MDC) skills. It is imperative that nursing educators discover the most effective teaching methodology to ensure the greatest level of competency in MDC skills. The purpose of this causal-comparative quantitative study was to compare the effects of two teaching methodologies on senior-level nursing students' completion of program MDC requirements, mathematics self-efficacy, and MDC competency at program end. The sample consisted of 94 senior-level bachelor's degree nursing students from a southeastern United States university in the spring of 2015. Each participant completed a demographic questionnaire, Mathematics Self-Efficacy Scale (MSES), and MDC competency exam. Participants were assigned to one of two groups based on whether the participants completed MDC education in a stand-alone course or throughout the curriculum through self-learning modules. Chi-square and independent $t$-test results indicated that there were no statistical differences between the two groups (stand-alone course vs. self-learning modules) and ability to complete program MDC requirements, MSES scores, and MDC competency exam scores at program end. Data analysis using Chi-square and Fisher's Exact tests indicated a statistically significant, but weak, correlation between MSES scores and MDC competency exam scores. Findings from this study indicate teaching MDC to nursing students using a stand-alone course versus self-learning modules produces the same results in the students' ability to complete program MDC requirements, mathematics self-efficacy, and MDC competency at program end.
\end{abstract}

Key Words: Nursing student, Medication dosage calculation, Competency, Self-efficacy, Teaching methodologies, Medication error

\section{INTRODUCTION}

Medication errors and the difficulty nurses have with MDC skills is a problem worldwide. With the frequent occurrence of medication errors and the potentially lethal effects, MDC practices and accuracy are of utmost importance to patient safety. Studies have shown that both nursing students and practicing nurses have problems accurately calculating medication dosages. ${ }^{[1,2]}$ In a study by Fleming et al. (2014), the MDC skills of registered nurses entering employment at teaching hospitals were examined. ${ }^{[1]}$ Even without the "real world" stressors that come with administering medications, the overall test mean was $12.16(\mathrm{SD}=3.91)$, a dismal $60.08 \%$. Although accurate measurements of preventable adverse drug errors (ADE) are hard to attain, the World Health Organization (2017) ${ }^{[3]}$ estimates that the global cost of medication errors is $\$ 42$ billion annually. Medication errors also have a significant impact on human life. According to the WHO, an estimated 1.3 million people are injured daily due to medication errors in the United States. These statistics are alarming especially since medication errors are almost

*Correspondence: Kristie Riddle; Email: Kristie.Riddle@ selu.edu; Address: School of Nursing, Southeastern Louisiana University, United States. 
always preventable.

Some measures hospitals have implemented to reduce medication errors include computer versus written doctor's orders, barcodes on medications/arm bands, electronic medication administration records (eMAR), medication dispensing systems, and smart pumps. ${ }^{[4]}$ Despite these automated safeguards, medication errors still occur. Medication errors involving infusion rates are especially alarming as these medications are infused directly into the bloodstream and cannot be "taken back." Due to the high risk related to the medications and the situations in which these medications are administered, these types of errors are estimated to occur five times more than with other medications. ${ }^{[5]}$ Use of one, or all, of these technological advancements does not replace the nurse's duty to ensure the rights of safe medication administration: right patient, right drug, right dose, right time/frequency, right route, right reason, and right documentation. ${ }^{[6]}$

Self-efficacy is shown to positively correlate with performance in academic functioning. ${ }^{[7-10]}$ Bandura (1986) defined self-efficacy as the judgment of people's ability to organize and execute the processes of action required to accomplish their stated goals. ${ }^{[11]}$ Williams and Williams (2010) explained that self-efficacy is derived from an individual's past experience with success or failed attempts at task mastery. ${ }^{[12]}$ Students with low self-efficacy may have already established doubts in their abilities to perform certain tasks with success such as MDC. These individuals avoid challenges and have lower aspirations and goals. Williams and Williams (2010) proposed that not only does perceived selfefficacy in math influence performance but that performance reciprocally affects the individual's math self-efficacy in a dynamic process. Findings from this work provide support for Bandura's component of how performance achievement effects self-efficacy. Gregory et al. (2019) found structured interventions and instruction significantly improved students' self-efficacy in math. ${ }^{[13]}$ The increase in math self-efficacy was associated with positive math performance. Nursing educators need to determine educational strategies that will help students achieve self-efficacy and become competent in MDC.

To ensure patient safety, nurses must be competent in MDC skills. It is imperative that nursing educators discover the most effective teaching methodology to ensure the greatest level of competency in MDC. Most nursing students are required to complete some form of MDC education in their nursing curriculum. The MDC portion of the curriculum often consists of high stakes testing requiring the student to complete the exam(s) with $90 \%$ or higher accuracy. ${ }^{[14]}$

Published by Sciedu Press
Despite the high standards required for progression related to MDC skills, research continues to show that both current nursing students and active, practicing nurses have significant difficulty performing medication administration related tasks. ${ }^{[2]}$

The purpose of this study was to compare the MDC competency and self-efficacy of bachelor's degree nursing students based on teaching methodology. Two teaching methodologies were compared: self-learning modules and a standalone lecture course. Discovering relations between teaching methodology and the dependent variables, MDC competency and self-efficacy, will allow faculty to develop teaching and learning methodologies to promote successful acquisition of MDC skills.

\section{METHOD}

This study was conducted in one school of nursing located in the southeastern region of the United States. The hosting institution offered a four-year bachelor's degree program for pre-licensure nursing. A causal-comparative design was used for the research study. In this study, the differences between two pre-existing groups based on outcomes, or dependent variables were examined. All students holding senior-level status during the spring 2015 semester in the pre-licensure bachelor's degree program were recruited. The study utilized a convenience sample of two predetermined cohorts of senior-level nursing students. Participation was on a voluntary basis, and each volunteer provided informed consent. Inclusion criteria for the control group included senior level program placement students who did not enroll in a standalone MDC course. Inclusion criteria for the experimental group included senior level placement in the nursing program and completion of a stand-alone MDC course.

Both groups in the study were subjected to different teachinglearning modalities regarding MDC skills. The groups received identical posttests during the senior level in the nursing curriculum to examine MDC competency and mathematics self-efficacy. All voluntary participants were administered a biographical questionnaire, MSES, and MDC competency exam. For the MSES, students were asked to complete 34 questions. The MSES is a two-part instrument with subscales of Everyday Math Tasks and Math Courses. The MSES assesses an individual's confidence in completing mathematics related tasks and courses. Betz and Hackett (1983) ${ }^{[15]}$ developed the MSES to measure students' confidence regarding ability to perform mathematics related tasks, with a Cronbach reliability coefficient alpha of 0.96 for the total scale.

The MDC competency exam consisted of 20 questions de- 
veloped by the researcher in collaboration with two nursing faculty with expertise in dosage calculation. The MDC competency exam addressed liquid and solid oral medications, injections, reconstitution, dilution of medications, infusion rates, titration adjustments, and determination of safe dose ranges. The data was then analyzed utilizing Statistical Package for the Social Sciences (SPSS). Prior to implementation, the researcher gained Institutional Review Board approval from the hosting university.

\section{Results}

\subsection{Description of sample}

The study participants consisted of senior-level nursing students $(\mathrm{N}=127)$ in a bachelor's degree nursing program. Ninety-four students participated in the study for a response rate of $74 \%$. The participants consisted of two groups of students. Students in one group were taught MDC through self-learning modules throughout the curriculum $(n=39)$, and those in the other group were taught via a stand-alone course at the start of nursing coursework $(n=55)$.

For participants that were taught via self-learning modules, the majority of participants fell into the category of 18-24 years of age $(34,87 \%)$. Most of the participants were female $(37,95 \%)$ and selected White for race $(38,97 \%)$. The majority of participants declared work status during school as part-time $(24,62 \%)$. The majority of students selected some college credits for educational level $(25,64 \%)$ and were not required to repeat a course in order to meet MDC competency requirements of the nursing program $(37,95 \%)$. The mean GPA of this group of participants was 3.69 (SD $=0.20$ ). Frequencies and percentages for nominal variables are presented in Table 1.

For the participants who were taught MDC via a stand-alone course, the majority of participants fell into the category of 18 -24 for age $(39,71 \%)$. Most of the participants were female $(48,87 \%)$ and selected White for race $(47,85 \%)$. The majority of participants declared work status during school as part-time $(34,62 \%)$. The majority of students reported some college credits for educational level $(28,51 \%)$ and were not required to repeat a course in order to meet MDC competency requirements of the nursing program $(54,98 \%)$. The mean GPA of this group of participants was 3.71 (SD $=0.19$ ). Frequencies and percentages for nominal variables are presented in Table 2.

\subsection{Research questions and hypotheses}

\subsubsection{Research Question 1}

Research Question 1 sought to determine whether nursing students attending a bachelor's degree program completed MDC requirements more successfully when taught as a stand- alone course at program start versus self-learning modules throughout the curriculum. The $\mathrm{H} 1$ states that there was no difference in the successful completion of MDC requirements of nursing students attending a bachelor's degree program when taught as a stand-alone course versus selflearning modules. To successfully complete program MDC requirements, students must obtain a score of $90 \%$ or higher on all MDC competency exams. If a student fails to achieve a minimum score of $90 \%$ on any MDC competency exam, the student was required to repeat the stand-alone course or the lab that corresponded with the self-learning module.

Table 1. Frequencies and percentages for nominal variables for self-learning module participant group

\begin{tabular}{|c|c|c|}
\hline Variables & $n$ & $\%$ \\
\hline \multicolumn{3}{|l|}{ Learning strategy } \\
\hline Self-learning Module & 39 & 100 \\
\hline \multicolumn{3}{|l|}{ Age } \\
\hline $18-24$ & 34 & 87 \\
\hline $25-34$ & 4 & 10 \\
\hline $45-54$ & 1 & 3 \\
\hline \multicolumn{3}{|l|}{ Gender } \\
\hline Female & 37 & 95 \\
\hline Male & 2 & 5 \\
\hline \multicolumn{3}{|l|}{ Race } \\
\hline Asian/Pacific Islander & 1 & 3 \\
\hline White & 38 & 97 \\
\hline \multicolumn{3}{|l|}{ Work status } \\
\hline During school breaks only & 4 & 10 \\
\hline Full-time & 2 & 5 \\
\hline Part-time & 24 & 62 \\
\hline Unemployed & 9 & 23 \\
\hline \multicolumn{3}{|l|}{ Educational level } \\
\hline Bachelor's degree & 2 & 5 \\
\hline High school & 10 & 26 \\
\hline Some college & 25 & 64 \\
\hline Trade/vocational & 2 & 5 \\
\hline \multicolumn{3}{|l|}{ Repeat dosage course } \\
\hline No & 37 & 95 \\
\hline Yes & 2 & 5 \\
\hline
\end{tabular}

A chi-square was conducted to assess the relationship between students required to repeat an MDC and teaching methodology. The variable of repeating a course had two levels: no and yes. The variable teaching methodology had two levels: Course and Self Modules. Prior to analysis, the assumption of adequate cell size was assessed by viewing expected values. For the assumption to be met, all cells must have expected values above 1.00 , and no more than $20 \%$ 
of the cells should have expected values that are less than 5.00. The assumption was not met, and thus the Fisher's Exact Test was conducted in place of the chi-square test of independence. The result of the Fisher's Exact test was not significant, $p=.568$, suggesting there was not a relationship between students repeating courses and teaching methodology, or failure to reject the null hypothesis (see Table 3).

Table 2. Frequencies and percentages for nominal variables for stand-alone course participant group

\begin{tabular}{|c|c|c|}
\hline Variables & $n$ & $\%$ \\
\hline \multicolumn{3}{|l|}{ Learning strategy } \\
\hline Course & 55 & 100 \\
\hline \multicolumn{3}{|l|}{ Age } \\
\hline $18-24$ & 39 & 71 \\
\hline $25-34$ & 13 & 24 \\
\hline $35-44$ & 3 & 5 \\
\hline \multicolumn{3}{|l|}{ Gender } \\
\hline Female & 48 & 87 \\
\hline Male & 7 & 13 \\
\hline \multicolumn{3}{|l|}{ Race } \\
\hline African American & 3 & 5 \\
\hline Asian/Pacific Islander & 4 & 7 \\
\hline Other & 1 & 2 \\
\hline White & 47 & 85 \\
\hline \multicolumn{3}{|l|}{ Work Status } \\
\hline During school breaks & 4 & 7 \\
\hline Full-time & 3 & 5 \\
\hline Part-time & 34 & 62 \\
\hline Unemployed & 14 & 25 \\
\hline \multicolumn{3}{|l|}{ Educational level } \\
\hline Associates degree & 1 & 2 \\
\hline Bachelor's degree & 16 & 29 \\
\hline High school & 9 & 16 \\
\hline Some college & 28 & 51 \\
\hline Trade/vocational & 1 & 2 \\
\hline \multicolumn{3}{|l|}{ Repeat dosage course } \\
\hline No & 54 & 98 \\
\hline Yes & 1 & 2 \\
\hline
\end{tabular}

Note. Due to rounding error, percentages may not add up to 100.

\subsubsection{Research Question 2}

Research Question 2 attempted to discover whether nursing students attending a bachelor's degree program demonstrate greater MDC competency at program end when taught MDC skills at the beginning of the curriculum in a stand-alone course or throughout the curriculum from self-learning modules. The $\mathrm{H} 2$ states there was no difference in the MDC competency at program end in nursing students attending a bachelor's degree program when taught MDC skills at the beginning of the curriculum in a stand-alone course versus throughout the curriculum from self-learning modules.

Table 3. Chi-Square between repeating course and teaching methodology

\begin{tabular}{lllll}
\hline \multirow{2}{*}{ Rpt_course } & \multicolumn{2}{l}{ teaching methodology } & \multirow{2}{*}{$\chi^{2}(\mathbf{1})$} & $\boldsymbol{p}$ \\
\cline { 2 - 3 } & Course & Self Modules & & \\
\hline No & $54[53.2]$ & $37[37.8]$ & - & .568 \\
Yes & $1[1.8]$ & $2[1.2]$ & & \\
\hline
\end{tabular}

Note. For each cell, numbers outside brackets represent observed values, while numbers in brackets represent the expected values of the cell. Fisher's Exact Test was conducted due to violations in the assumptions, thus no chisquare statistic was calculated.

Participants were administered a 20-item MDC competency exam. One point was assigned to each correct answer. The total number of points was then divided by the total number of items to formulate a percentage score on the exam for each participant. The MDC competency exam scores ranged from $50 \%-95 \%$ with a mean of $72.95 \%(\mathrm{SD}=12.655)$ for the self-module group and 30\%-95\% with a mean of $69.09 \%$ $(\mathrm{SD}=16.917)$ for the stand-alone course group.

The group taught via self-learning modules received a formal MDC competency exam following the completion of each self-learning module, for a total of four semesters. Their most recent exam linked to a self-learning module was completed the semester prior to this study. The group of participants taught MDC skills in a stand-alone course received the last formal MDC competency exam three semesters prior to this study.

An independent sample $t$-test was conducted to assess whether there were differences in MDC competency exam scores by teaching methodology (Course vs. Self-Modules). Prior to analysis, the assumption of normality was assessed using a Shapiro-Wilk test. The result of the test was significant, $p=.009$, violating the assumption of normality. However, Howell (2017) suggests that the $t$-test is robust despite violations of normality when the independent sample sizes are greater than $30 .{ }^{[16]}$ The assumption of equality of variance was assessed using Levene's test. The result of the test was not significant, $p=.125$, indicating the assumption of equality of variance was met.

The results of the independent sample $t$-test were not significant, $t(92)=-1.20, p=.232$, suggesting that there was not a difference in MDC competency exam score by teaching methodology, or failure to reject the null hypothesis (see Table 4).

\subsubsection{Research Question 3}

Research Question 3 asked whether there are differences in mathematics self-efficacy between students who are taught 
MDC skills as a stand-alone course versus self-learning modules throughout the curriculum. The $\mathrm{H} 3$ states that there was no difference in mathematics self-efficacy between students who are taught MDC skills as a stand-alone course versus self-learning modules throughout the curriculum.

Table 4. Independent sample $t$-Test for dosage calculation exam by teaching methodology

\begin{tabular}{|c|c|c|c|c|c|c|c|}
\hline \multirow{2}{*}{ Variable } & \multirow{2}{*}{$t(92)$} & \multirow{2}{*}{$p$} & \multicolumn{3}{|c|}{ Course } & \multicolumn{2}{|c|}{ Self Modules } \\
\hline & & & Cohen's d & M & SD & $\mathbf{M}$ & SD \\
\hline Exam & -1.20 & .232 & 0.26 & 69.09 & 16.92 & 72.95 & 12.66 \\
\hline
\end{tabular}

The MSES tool consists of 34 items, to which the participant responds on a Likert scale of 0-9, for a total of 0-306. To obtain the participants' scores on the MSES, the sum of all responses were divided by 306 to form a percentage score on the instrument. The MSES scores from the self-learning modules group ranged from $43.14 \%-97.06 \%$ with a mean of $74.68 \%$ ( $\mathrm{SD}=13.23$ ). The score range for the stand-alone course group was $57.84 \%-99.35 \%$ with a mean of $78.93 \%$ $(\mathrm{SD}=10.69)$.

An independent sample $t$-test was conducted to assess whether there were differences in MSES score by teaching methodology (Course vs. Self-Modules). Prior to analysis, the assumption of normality was assessed using a ShapiroWilk test. The result of the test was not significant, $p=.101$, validating the assumption of normality. The assumption of equality of variance was assessed using Levene's test. The result of the test was not significant, $p=.075$, indicating the assumption of equality of variance was met.

The results of the independent sample $t$-test were not significant, $t(92)=1.72, p=.089$, suggesting that there was not a difference in MSES score by teaching methodology, or failure to reject the null hypothesis (see Table 5).

Table 5. Independent sample $t$-Test for MSES score by teaching methodology

\begin{tabular}{|c|c|c|c|c|c|c|c|}
\hline \multirow{2}{*}{ Variable } & \multirow{2}{*}{$t(92)$} & \multirow{2}{*}{$p$} & \multirow{2}{*}{$\begin{array}{l}\text { Cohen's } \\
\text { d }\end{array}$} & \multicolumn{2}{|c|}{ Course } & \multicolumn{2}{|c|}{ Self Modules } \\
\hline & & & & $\mathbf{M}$ & SD & $\mathbf{M}$ & SD \\
\hline MSES score & 1.72 & .089 & 0.35 & 78.93 & 10.69 & 74.68 & 13.23 \\
\hline
\end{tabular}

\subsubsection{Research Question 4}

Research Question 4 inquired whether there was a relationship between mathematics self-efficacy and MDC competency exam scores. The $\mathrm{H} 4$ states that there was no relationship between mathematics self-efficacy and MDC competency exam scores. A Pearson correlation matrix was created among MDC competency exam and MSES scores. Although the correlation was weak, it showed that MDC competency exam scores were significantly correlated with MSES scores (see Table 6). A significant positive correlation, $r(94)=$
$0.232, p=.024$, indicated that as one variable increases, the other variable also tends to increase; therefore, the null hypothesis was rejected.

Table 6. Correlation matrix among MDC competency exam and MSES scores

\begin{tabular}{llll}
\hline & & Dosage Exam & Self-Efficacy \\
\hline \multirow{2}{*}{ Dosage exam } & Pearson Correlation & 1 & $.232^{*}$ \\
& Sig. (2-tailed) & & 0.024 \\
& $\mathrm{~N}$ & 94 & 94 \\
& Pearson Correlation & $.232^{*}$ & 1 \\
Self-Efficacy & Sig. (2-tailed) & 0.024 & \\
& $\mathrm{~N}$ & 94 & 94 \\
\hline${ }^{*} p \leq .050$ & & &
\end{tabular}

\section{Discussion AND CONCLUSION}

Nurses are the primary administrators of medications and the last line of defense between patients and medication errors. Nurses are educated in MDC skills during the pre-license nursing curriculum. Nursing education often requires a high level of accuracy, greater than or equal to $90 \%$, and high stakes testing. ${ }^{[14]}$ Despite nursing students' abilities to successfully complete the their program's MDC competency requirements, studies show that both nursing students and currently practicing nurses have problems accurately calculating medication dosages. ${ }^{[1,2]}$ According to Simonsen et al., $(2014)^{[2]}$ although nurses performed significantly better than students in pharmacological knowledge, drug management, and drug calculations, the researchers found this marginal improvement to not be clinically significant. These researchers surmised that both groups had insufficient knowledge in medication administration and posed a high risk for error. While all students in this study successfully completed program MDC requirements with a $90 \%$ or higher, the participants performed at a much lower level on the study's MDC competency exam.

Lazare (2018) ${ }^{[17]}$ found students believed that content retention was linked to continuous practicing of material learned in the classroom whether it be alone, in groups, or during clinical practicums. With one group having more recent performance achievement, one might expect this group to exhibit better performance on the MDC competency exam in this study. ${ }^{[18]}$ Even though the results were not significant, the students who most recently completed their MDC (self-module group) scored higher on the MDC exam.

In addition to performance achievement, Bandura (1994) ${ }^{[19]}$ proposes that individuals can gain a sense of self-efficacy through social modeling and positive verbal persuasion. Social modeling states that by observing others, similar to one's self, achieve task competencies, individuals can model the

ISSN 1925-4040 E-ISSN 1925-4059 
behavior to achieve goals and self-efficacy. Positive verbal persuasion helps boost perseverance, while prosocial orientation can increase self-efficacy and academic functioning through decreasing depression and problem behaviors. ${ }^{[18,19]}$ In this study, statistical significance was found through a weak, positive correlation between MSES and MDC exam scores.

This study also supports that MDC competency is a serious problem for nursing education, the practice of nursing, and patient health and safety. These results imply a need for further investigation into self-efficacy, teaching, and learning related to MDC skills in nursing education and practice. Faculty should examine curriculum, teaching methodologies and student performance for their own programs to determine areas that need modification in order to help ensure student MDC competency. Faculty should also make sure to implement MDC skills throughout the curriculum and al-

\section{REFERENCES}

[1] Fleming S, Brady A, Malone A. An evaluation of the drug calculation skills of registered nurses. Nursing Education in Practice. 2014; 14: 55-61. PMid:23831386 https://doi.org/10.1016/j .nepr .2013 .06 .002

[2] Simonsen BO, Daehlin GK, Johansson I, et al. Differences in medication knowledge and risk of errors between graduating nursing students and working registered nurses: Comparative study. BMC Health Service Research. 2014; 14: 580. PMid:25413244 https://doi.org/10.1186/s12913-014-0580-7

[3] World Health Organization. WHO launches global effort to halve medication-related errors in 5 years. 2017. Available from: https://www. who.int/news-room/detail/29-03-2017-w ho-launches-global-effort-to-halve-medication-rel ated-errors-in-5-years

[4] Manias E, William E, Liew D. Interventions to reduce medication errors in adult intensive care: A systematic review. British Journal of Clinical Pharmacology. 2012; 74(3): 411-423. PMid:22348303 https://doi.org/10.1111/j.1365-2125.2012.04220.x

[5] Wolf ZR, Hughes RG. Best practices to decrease infusion-associated medication errors. Journal of Infusion Nursing. 2019; 42(4): 183-192. PMid:31283660 https://doi.org/10.1097/NAN. 0000000000 000329

[6] Smeulers M, Verweij L, Maaskant JM, et al. Quality indicators for safe medication preparation and administration: A systematic review. PLoS ONE. 2015; 10(4): e0122695. PMid:25884623 https://doi.org/10.1371/journal.pone.0122695

[7] Roick J, Ringeisen T. Students' math performance in higher education: Examining the role of self-regulated learning and selfefficacy. Learning \& Individual Differences. 2018; 65: 148-158. https://doi.org/10.1016/j.lindif.2018.05.018

[8] Mirick RG, Davis A. Making meaning of MSW students' statistical abilities: The role of self-efficacy and knowledge-based assessment. Journal of Social Work Education. 2017; 53(2): 212-221. https://doi.org/10.1080/10437797.2016.1269702

[9] Alrabai F. The association between self-efficacy of Saudi learners and their EFL academic performance. Theory and Practice in Language low students numerous opportunities to practice these skills. Since MSES has a significant positive correlation with MDC competency, incorporating practices such as positive verbal persuasion, modeling, and promoting prosocial classroom behaviors.

With unequal groups, small sample size, and the inability to manipulate variables, future studies are needed in the area of nursing MDC. Through the use of larger cohorts, multiple schools of nursing, different levels of nursing education, and a variety of teaching strategies, future research has the potential to present more complete and comprehensive data regarding factors to increase MDC skill acquisition and retention. Future research should focus on the impact of the classroom environment and faculty teaching style on student learning and self-efficacy.

\section{CONFlicts of InTEREST Disclosure}

The authors declare that there is no conflict of interest.
Studies. 2018; 10: 1351. https://doi.org/10.17507/tpls.08 10.14

[10] Sun W, Huang Y. Research on relationships among achievement goals, self-efficacy and academic performance of students in Shandong Province. International Journal of Organizational Innovation. 2019; 12(1): 280-289.

[11] Bandura A. Social Foundations of Thought and Action: A Social Cognitive Theory. Englewood Cliffs: Prentice Hall. 1986.

[12] Williams T, Williams K. Self-efficacy and performance in mathematics: Reciprocal determinism in 33 nations. Journal of Educational Psychology. 2010; 102(2): 453-466. https://doi.org/10.1037/ a0017271

[13] Gregory L, Villarosa AR, Ramjan LM, et al. The influence of mathematics self-efficacy on numeracy performance in first-year nursing students: A quasi-experimental study. Journal of Clinical Nursing. 2019; $1-9$.

[14] Roykenes K, Smith K, Larsen T. 'It is the situation that makes it difficult': Experiences of nursing students faced with high-stakes drug calculation test. Nursing Education in Practice. 2014; 14(4): 350-356. PMid:24462630 https://doi.org/10.1016/j.nepr.2014.01 .004

[15] Betz NE, Hackett G. The relationship of mathematics self-efficacy expectations to the selection of science-based college majors. Journal of Vocational Behavior. 1983; 23: 329-345. https ://doi . org/10 .1016/0001-8791(83) 90046-5

[16] Howell DC. Fundamental statistics for the behavioral sciences. 9th ed. Boston, MA: Cengage Learning. 2017.

[17] Lazare MB. The lived experiences of undergraduate nursing students learning drug dosage calculation. International Journal of Nursing \& Clinical Practices. 2018; 5: 297. https://doi .org/10.15344/2 394-4978/2018/297

[18] Bandura A, Barbaranelli C, Caprara G, et al. Mulitfaceted impact of self-efficacy beliefs on academic functioning. Child Development. 1996; 67(3): 1206-1222. https://doi .org/10.2307/1131888

[19] Bandura A. Self-efficacy: Toward a unifying theory of behavioral change. Psychological Review. 1994; 84: 191-215. https: //doi.org/10.1037/0033-295X.84.2.191 